\title{
Evaluation of Intraperitoneal Instillation of Levobupivacaine versus Ultrasound Guided Rectus Sheath Block for Post-Operative Pain Relief Following Laparoscopic Cholecystectomy
}

\author{
Ahmed A. Metwally, Nagwa M. Doha, Amany A. Sultan, Hend A. Okasha* \\ Department of Anesthesiology, Intensive Care and Pain Management, Faculty of Medicine, Menoufia University, \\ Egypt. \\ *Corresponding author: Hend A. Okasha, Mobile: (+20) 01220593448, E-Mail: hendokasha93@gmail.com
}

\begin{abstract}
Background: Laparoscopic cholecystectomy (LC) is not a painless process, with the most acute pain occurring on the day of surgery and the next day. Postoperative pain management methods include intraperitoneal instillation of local anaesthetics and rectus sheath block (RSB), both of which may give excellent pain reduction.

Objectives: The aim of this study was to evaluate the efficacy of intraperitoneal instillation versus rectus sheath block using levobupivacaine for postoperative pain relief after laparoscopic cholecystectomy.

Patients and methods: The study was a prospective randomized double-blind study. Patients were randomized into two groups using a closed envelope technique in sequentially numbered opaque envelopes that was opened by an anesthesiologist not involved in the study. The study was conducted on 50 patients, 25 each for each group. Group I received intraperitoneal instillation of $40 \mathrm{ml} 0.25 \%$ levobupivacaine. Group II (Rectus sheath block) received bilateral RSB with $40 \mathrm{ml}$ of $0.25 \%$ levobupivacaine ( $20 \mathrm{ml}$ on each side).

Results: There was high statistical significant difference between groups as regard VAS. There was high statistical significant difference between groups as regards patient satisfaction, which was more increased among rectus sheath group. Conclusion: U/S-guided rectus sheath block is effective as analgesic technique as intraperitoneal instillation of levobupivacaine led to more patient satisfaction, lower postoperative pain and lower amount of anaesthetic consumption. Both techniques are simple, safe, and without adverse effects. This study favors the administration of rectus sheath block pre-emptively for postoperative pain relief after laparoscopic cholecystectomy.
\end{abstract}

Keywords: Laparoscopic Cholecystectomy, Intraperitoneal Instillation, Levobupivacaine rectus sheath block.

\section{INTRODUCTION}

In the treatment of gallbladder illness, LC has replaced open surgery as the preferred method ${ }^{(1)}$. Parenteral analgesia (NSAIDS and opioids), epidural analgesia, peripheral nerve block, incisional infiltration, and intraperitoneal instillation utilising local anaesthetics are all options for postoperative pain management ${ }^{(2)}$.

Prevention of transmission of nerve signals from the trauma site to the spinal cord and reduction of neurogenic local inflammation at the trauma site has been reported with the use of local anesthetics. As large volumes are required in these techniques, levobupivacaine, a newer amide may be preferred due to less risk of cardiovascular toxicity and central nervous system side effects. Intraperitoneal local anesthetic administration and rectus sheath block (RSB) have been used as a methods for reducing postoperative pain ${ }^{(3)}$.

Intraperitoneal local anesthetics acts on visceral nociceptors of peritoneum whereas rectus sheath block, with successful blockade of intercostal nerves, provides full thickness anesthesia of anterior abdominal wall ${ }^{(4)}$. Individual studies have been conducted to evaluate the efficacy of intraperitoneal instillation of local anaesthetics and RSB, but we have not found any studies comparing the efficacy of intraperitoneal instillation versus RSB to determine which is superior for postoperative pain relief after $\mathrm{LC}^{(3)}$.
The aim of this study was to evaluate the efficacy of intraperitoneal instillation versus rectus sheath block using levobupivacaine for postoperative pain relief after laparoscopic cholecystectomy.

\section{PATIENTS AND METHODS}

This study was conducted in the operative theatres of Menoufia University Hospitals. The study was a prospective randomized double-blind study. Patients were randomized into two groups using a closed envelope technique in sequentially numbered opaque envelopes that was opened by an anesthesiologist not involved in the study.

The study was conducted on 50 patients, 25 for each group. Group I (Intraperitoneal instillation) received intraperitoneal instillation of $40 \mathrm{ml} 0.25 \%$ levobupivacaine. Group II (Rectus sheath block) received bilateral RSB with $40 \mathrm{ml}$ of $0.25 \%$ levobupivacaine ( $20 \mathrm{ml}$ on each side).

Postoperative: If VAS is $\geq 4$ the patient was given Ketorolac $30 \mathrm{mg}$ IV slowly. If after half an hour VAS is still $\geq 4$, the patient was given $25 \mathrm{mg}$ pethidine, which was repeated every 30 minutes till VAS is $<4$.

\section{Data Collection:}

Baseline: Patients' demographic data and hemodynamics (pulse- heart rate- mean blood pressure), baseline before induction of anesthesia were recorded. 
Intraoperative: Hemodynamics (pulse- heart ratemean blood pressure).

They was assessed as follow: After 5 minutes after induction of anesthesia then every $15 \mathrm{~min}$ till end of the surgery. Total anesthetic and analgesic consumption needed to reach target entropy measurement 40-60. The anesthetic time (it is the time that starts when the anesthesia provider begins to administer the IV anesthetics and ends with tracheal extubation) and surgical time (starts with skin incision and ends with last suture and putting dressings on). The time taken for the block. Number of patients needed ephedrine and/or atropine and total amount of their administration was recorded. Recovery time (time since anesthetics discontinuation till reaching score 9 of Alderete's criteria).

Postoperative: Time of first call for rescue analgesia. Number of patients requested analgesia postoperatively. Visual analogue scale (VAS) on admission to postanesthetic care unit (PACU), every 30 minutes for next 2 hours, every 2 hours for next 6 hours and every 6 hours for remaining 24 hours post-operatively. Hemodynamics (pulse- heart rate- mean blood pressure) was assessed on admission to post-anesthetic care unit (PACU) every 15,30,60,90,120 minutes then every 2 hours for next 6 hours then every 6 hours for remaining 24 hours. Discharge from PACU was according to Postanesthesia Discharge Scoring System. Vomiting, nausea and starting time of intestinal movements. Duration of the block (from the injection time of local anesthetic till complete return of sensation). Patients' satisfaction with analgesia at the time discharge was evaluated based on a 5-point Likert scale as follow: $(0=$ weak, $1=$ moderate, $2=$ good, $3=$ very good and $4=$ excellent).

After 2 and $24 \mathrm{~h}$, the sites of injection of the rectus sheath block or intraperitoneal instillation was examined to detect any local complications.

\section{Ethical approval:}

The study protocol was approved by Research and Ethics Committee of the Department of Anesthesia, ICU and Pain Management, Faculty of Medicine, Menoufia University. A written informed consent was obtained from each patient. This work has been carried out in accordance with The Code of Ethics of the World Medical Association (Declaration of Helsinki) for studies involving humans.

\section{Statistical analysis}

Data were fed to the computer and analyzed using IBM SPSS software package version 20.0. (Armonk, NY: IBM Corp). Qualitative data were described using number and percent. The Kolmogorov-Smirnov test was used to verify the normality of distribution. Quantitative data were described using range (minimum and maximum), mean \pm standard deviation and median. Significance of the obtained results was judged at the $5 \%$ level. $\mathrm{P}$ value $\leq 0.05$ was considered significant.

\section{RESULTS}

Table (1) showed that group I included 6 males (24\%) and 19 females ( $76 \%$ ). Their ages ranged from 28.0 to 50.0 years (mean was $41.36 \pm 5.93$ ). Group II included 9 males $(36 \%)$ and 16 females (64\%). Their ages ranged from 20.0 to 50.0 years (mean was $41.0 \pm 7.05$ ). There was no statistical significant difference between groups as regards sex and Age.

Table (2) showed that there was high statistical significant difference between groups as regards MAC and Fentanyl consumption.

Table (3) showed that there was no statistical significant difference between groups regarding anesthetic time and surgical time (min) but there was high statistical significant difference between groups as regards duration of the block, recovery time and time taken for the block.

Table (4) showed that there was high statistical significant difference between groups as regards total analgesic consumption postoperatively.

Table (5) showed that there was high statistical significant difference between groups as regards first call for rescue analgesia hours.

Table (6) showed that there was high statistical significant difference between groups as regards VAS.

Table (7) showed that there was high statistical significant difference between groups as regards patient satisfaction.

Table (1): Comparison between the two studied groups according to demographic data

\begin{tabular}{|c|c|c|c|c|c|c|}
\hline & \multicolumn{2}{|c|}{$\begin{array}{l}\text { Group I } \\
(n=25)\end{array}$} & \multicolumn{2}{|c|}{$\begin{array}{c}\text { Group II } \\
(\mathrm{n}=\mathbf{2 5})\end{array}$} & \multirow[t]{2}{*}{ Test of Sig. } & \multirow[t]{2}{*}{$\mathbf{p}$} \\
\hline & No. & $\%$ & No. & $\%$ & & \\
\hline \begin{tabular}{|l|} 
Sex \\
Male \\
Female
\end{tabular} & $\begin{array}{c}6 \\
19\end{array}$ & $\begin{array}{l}24.0 \\
76.0\end{array}$ & $\begin{array}{c}9 \\
16\end{array}$ & $\begin{array}{l}36.0 \\
64.0\end{array}$ & $\begin{array}{c}\chi^{2}= \\
0.857\end{array}$ & 0.355 \\
\hline Age (years) & \multicolumn{2}{|c|}{$41.36 \pm 5.93$} & \multicolumn{2}{|c|}{$41.0 \pm 7.05$} & $\mathrm{t}=0.195$ & 0.846 \\
\hline \begin{tabular}{|l|} 
Weight (kg) \\
\end{tabular} & \multicolumn{2}{|c|}{$84.76 \pm 8.55$} & \multicolumn{2}{|c|}{$85.72 \pm 6.87$} & $\mathrm{t}=0.438$ & 0.664 \\
\hline
\end{tabular}

Data were expressed by using Mean \pm SD comparing between the studied groups Group I: $\chi^{2}$ : Chi square test $\quad t$ : Student t-test P: $p$ value for Intra peritoneal instillation Group II: Rectus sheath block 
Table (2): Comparison between the two studied groups according to anesthetic consumption

\begin{tabular}{|l|c|c|c|c|}
\hline Anesthetic consumption & $\begin{array}{c}\text { Group I } \\
(\mathbf{n = 2 5})\end{array}$ & $\begin{array}{c}\text { Group II } \\
(\mathbf{n = 2 5})\end{array}$ & $\mathbf{p}$ \\
\hline MAC & $1.56 \pm 0.17$ & $1.24 \pm 0.10$ & $8.377^{*}$ & $<0.001^{*}$ \\
\hline Fentanyl consumption & $135.2 \pm 25.51$ & $92.0 \pm 19.58$ & $6.716^{*}$ & $<0.001^{*}$ \\
\hline
\end{tabular}

Data was expressed by using Mean \pm SD $\quad$ t: Student t-test $\quad \mathrm{p}$ : $\mathrm{p}$ value for comparing between the studied groups*: Statistically significant at $\mathrm{p} \leq 0.05$ Group I: $\quad$ Intra peritoneal instillation Group II: Rectus sheath block

Table (3): Comparison between the two studied groups according to times of regional technique data

\begin{tabular}{|l|c|c|r|r||}
\hline Times of operative data & $\begin{array}{c}\text { Group I } \\
(\mathbf{n = 2 5})\end{array}$ & $\begin{array}{c}\text { Group II } \\
(\mathbf{n = 2 5})\end{array}$ & $\mathbf{p}$ \\
\hline Anesthetic time (min) & $66.20 \pm 12.77$ & $68.24 \pm 14.89$ & 0.520 & 0.605 \\
\hline Surgical time (min) & $51.80 \pm 11.80$ & $52.80 \pm 12.51$ & 0.291 & 0.773 \\
\hline $\begin{array}{l}\text { Duration of the block } \\
\text { (hr.) }\end{array}$ & $2.24 \pm 0.44$ & $5.32 \pm 0.75$ & $17.782^{*}$ & $0.001^{*}$ \\
\hline Recovery time & $10.20 \pm 3.08$ & $14.76 \pm 2.85$ & $5.434^{*}$ & $0.001^{*}$ \\
\hline Time taken for the block & $3.0 \pm 0.0$ & $14.16 \pm 2.43$ & $22.992^{*}$ & $0.001^{*}$ \\
\hline
\end{tabular}

Data was expressed by using Mean \pm SD $\quad \mathrm{t}$ : Student t-test $\mathrm{p}$ : $\mathrm{p}$ value for comparing between the studied groups *: Statistically significant at $\mathrm{p} \leq 0.05$ Group I: $\quad$ Intra peritoneal instillation Group II: Rectus sheath block

Table (4): Comparison between the two studied groups according to total analgesic consumption postoperative

\begin{tabular}{|c|c|c|c|c|}
\hline $\begin{array}{c}\text { Total analgesic } \\
\text { consumption } \\
\text { postoperative }\end{array}$ & $\begin{array}{c}\text { Group I } \\
(\mathbf{n = 2 5})\end{array}$ & $\begin{array}{c}\text { Group II } \\
(\mathbf{n}=\mathbf{2 5})\end{array}$ & $\mathbf{p}$ \\
\hline Mean \pm SD. & $270.4 \pm 26.53$ & $66.40 \pm 31.51$ & $24.762^{*}$ & $<0.001^{*}$ \\
\hline
\end{tabular}

Data was expressed by using Mean \pm SD $\quad$ t: Student t-test

$\mathrm{p}$ : $\mathrm{p}$ value for comparing between the studied groups $\quad *$ : Statistically significant at $\mathrm{p} \leq 0.05 \quad$ Group I:

Intra peritoneal instillation Group II:

Rectus sheath block

Table (5): Comparison between the two studied groups according to postoperative of first call for rescue analgesia hours

\begin{tabular}{|c|c|c|c|c|}
\hline $\begin{array}{l}\text { Postoperative first call } \\
\text { for rescue analgesia } \\
\text { (hours) }\end{array}$ & $\begin{array}{l}\text { Group I } \\
(n=25)\end{array}$ & $\begin{array}{c}\text { Group II } \\
(n=25)\end{array}$ & $\mathbf{t}$ & $\mathbf{p}$ \\
\hline Mean \pm SD & $2.88 \pm 0.33$ & $5.32 \pm 0.69$ & $15.928^{*}$ & $<0.001^{*}$ \\
\hline
\end{tabular}

Data was expressed by using Mean \pm SD $\quad$ t: Student t-test groups $\quad *$ : Statistically significant at $\mathrm{p} \leq 0.05 \quad$ Group I:

Rectus sheath block $\mathrm{p}$ : $\mathrm{p}$ value for comparing between the studied Intra peritoneal instillation Group II: 
Table (6): Comparison between the two studied groups according to VAS

\begin{tabular}{|c|c|c|c|c|c|c|}
\hline $\begin{array}{c}\text { Post-operative of } \\
\text { VAS } \\
\end{array}$ & $\begin{array}{c}\text { Intra peritoneal } \\
\text { instillation }(n=25)\end{array}$ & $\mathbf{p}_{0}$ & $\begin{array}{c}\begin{array}{c}\text { Rectus sheath block } \\
(\mathrm{n}=25)\end{array} \\
\end{array}$ & $\mathbf{p}_{0}$ & $\mathbf{U}$ & $\mathbf{p}$ \\
\hline $\begin{array}{l}\mathbf{3 0} \text { min } \\
\text { Median (Min. - Max.) } \\
\text { Mean } \pm \text { SD. }\end{array}$ & $\begin{array}{c}3.0(3.0-4.0) \\
3.12 \pm 0.33\end{array}$ & & $\begin{array}{c}2.0(2.0-3.0) \\
2.12 \pm 0.33\end{array}$ & & $33.0^{*}$ & $<0.001^{*}$ \\
\hline $\begin{array}{l}\mathbf{6 0} \text { min } \\
\text { Median (Min. - Max.) } \\
\text { Mean } \pm \text { SD. }\end{array}$ & $\begin{array}{c}3.0(3.0-4.0) \\
3.12 \pm 0.33 \\
\end{array}$ & 1.000 & $\begin{array}{c}2.0(2.0-3.0) \\
2.12 \pm 0.33 \\
\end{array}$ & 1.000 & $33.0^{*}$ & $<0.001^{*}$ \\
\hline $\begin{array}{l}90 \text { min } \\
\text { Median (Min. - Max.) } \\
\text { Mean } \pm \text { SD. }\end{array}$ & $\begin{array}{c}3.0(3.0-4.0) \\
3.24 \pm 0.44\end{array}$ & 0.535 & $\begin{array}{c}2.0(2.0-3.0) \\
2.12 \pm 0.33 \\
\end{array}$ & 1.000 & $28.50^{*}$ & $<0.001^{*}$ \\
\hline $\begin{array}{l}\mathbf{2} \text { hr. } \\
\text { Median (Min. - Max.) } \\
\text { Mean } \pm \text { SD. }\end{array}$ & $\begin{array}{c}4.0(4.0-5.0) \\
4.08 \pm 0.28\end{array}$ & $<0.001^{*}$ & $\begin{array}{c}3.0(3.0-3.0) \\
3.0 \pm 0.0\end{array}$ & $<0.001^{*}$ & $0.0^{*}$ & $<0.001^{*}$ \\
\hline $\begin{array}{l}\text { 4hr. } \\
\text { Median (Min. - Max.) } \\
\text { Mean } \pm \text { SD. }\end{array}$ & $\begin{array}{c}4.0(4.0-5.0) \\
4.24 \pm 0.44 \\
\end{array}$ & $<0.001^{*}$ & $\begin{array}{c}3.0(3.0-4.0) \\
3.12 \pm 0.33 \\
\end{array}$ & $<0.001^{*}$ & $28.50^{*}$ & $<0.001^{*}$ \\
\hline $\begin{array}{l}\text { 6hr. } \\
\text { Median (Min. - Max.) } \\
\text { Mean } \pm \text { SD. }\end{array}$ & $\begin{array}{c}5.0(4.0-5.0) \\
4.88 \pm 0.33\end{array}$ & $<0.001^{*}$ & $\begin{array}{c}4.0(4.0-4.0) \\
4.0 \pm 0.0\end{array}$ & $<0.001^{*}$ & $37.50^{*}$ & $<0.001^{*}$ \\
\hline $\begin{array}{l}\text { 12hr. } \\
\text { Median (Min. - Max.) } \\
\text { Mean } \pm \text { SD. }\end{array}$ & $\begin{array}{c}4.0(3.0-5.0) \\
3.64 \pm 0.70\end{array}$ & $0.006^{*}$ & $\begin{array}{c}2.0(2.0-4.0) \\
2.60 \pm 0.71\end{array}$ & $0.011^{*}$ & $105.0^{*}$ & $<0.001^{*}$ \\
\hline $\begin{array}{l}\text { 18hr. } \\
\text { Median (Min. - Max.) } \\
\text { Mean } \pm \text { SD. }\end{array}$ & $\begin{array}{c}3.0(3.0-5.0) \\
3.32 \pm 0.56\end{array}$ & 0.290 & $\begin{array}{c}2.0(2.0-4.0) \\
2.44 \pm 0.71\end{array}$ & 0.084 & $108.0^{*}$ & $<0.001^{*}$ \\
\hline $\begin{array}{l}\text { 24hr. } \\
\text { Median (Min. - Max.) } \\
\text { Mean } \pm \text { SD. }\end{array}$ & $\begin{array}{c}3.0(3.0-4.0) \\
3.08 \pm 0.28\end{array}$ & 0.897 & $\begin{array}{c}2.0(2.0-3.0) \\
2.12 \pm 0.33 \\
\end{array}$ & 1.000 & $34.50^{*}$ & $<0.001^{*}$ \\
\hline
\end{tabular}

Data was expressed by using Mean \pm SD $\quad$ U: Mann Whitney test $p: p$ value for comparing between the two studied groups $\quad \mathrm{p}_{0}$ : $\mathrm{p}$ value for Post Hoc Test (Dunn's) for Friedman test for comparing between post-operative of 30 min and different periods $\quad *$ : Statistically significant at $\mathrm{p} \leq 0.05$

Table (7): Comparison between the two studied groups according to patient satisfaction

\begin{tabular}{|l|c|c|c|c|c|c||}
\hline \multirow{2}{*}{ Patient satisfaction } & \multicolumn{2}{|c|}{$\begin{array}{c}\text { Group I } \\
(\mathbf{n = 2 5})\end{array}$} & \multicolumn{2}{c|}{$\begin{array}{c}\text { Group II } \\
(\mathbf{n = 2 5})\end{array}$} & \multirow{2}{*}{ Test of Sig. } & \multirow{2}{*}{ p } \\
\cline { 2 - 5 } & No. & \% & No. & \% & & \\
\hline 1 & 10 & 40.0 & 0 & 0.0 & & \\
2 & 15 & 60.0 & 3 & 12.0 & $\chi^{2}=$ & ${ }^{\mathrm{MC}_{\mathrm{p}}}$ \\
3 & 0 & 0.0 & 9 & 36.0 & $44.134^{*}$ & $<0.001^{*}$ \\
4 & 0 & 0.0 & 13 & 52.0 & & \\
\hline Mean \pm SD. & \multicolumn{2}{|c|}{$1.60 \pm 0.50$} & $3.40 \pm 0.71$ & $\mathrm{t}=10.39^{*}$ & $<0.001^{*}$ \\
\hline
\end{tabular}

Data was expressed by using Mean \pm SD $\quad \chi^{2}$ : Chi square test $\quad$ MC: Monte Carlo $\quad$ t: Student t-test $p: p$ value for comparing between the studied groups *: Statistically significant at $\mathrm{p} \leq 0.05$ Group I: Intra peritoneal instillation Group II: Rectus sheath block

\section{DISCUSSION}

The most commonly performed operation of the biliary tract these days is cholecystectomy, which is the second most common surgical procedure. Laparoscopic cholecystectomy (LC) has the advantage of less pain, shorter hospital stay and recovery period. Pain following LC is multifactorial and is differentiated into three components: visceral, abdominal wall, and referred pain to the shoulder. Visceral pain after laparoscopy results from the stretching of abdominal cavity, peritoneal inflammation, and phrenic nerve irritation caused by residual $\mathrm{CO}_{2}$ in the peritoneal cavity (5). Ultrasound (U/S) guidance allows for a greater reliability in administering local anesthetic in the correct plane and decreasing the remote potential for complications. Guiding the needle with U/S guidance to the posterior rectus sheath rather than relying on 'pops', such as in the traditional, non-U/S techniques, makes this block more reproducible and reduces the risk for inadvertent peritoneal and vascular punctures ${ }^{(6)}$.

The aim of the current study was to evaluate the efficacy of intraperitoneal instillation versus rectus 
sheath block using levobupivacaine for postoperative pain relief after laparoscopic cholecystectomy.

In the present study, the mean age of cases in group I was $41.36 \pm 5.93$ years old, and was $41.0 \pm 7.05$ years old in cases of group II, and there were nonstatistical significant differences between two groups as regards age, sex and weight. This is in agreement with the study of Gupta et al. ${ }^{(7)}$ who reported that mean age of intraperitoneal injection group was $46.04 \pm 13.68$, and in rectus sheath block group was $47.64 \pm 14.76$ years old, and there were non-statistical significant differences between the two groups as regard age, sex and weight. In contrast to our findings, the study of Gupta et al. ${ }^{(7)}$ reported that there was no significant intergroup variations in heart rate. Also, the study of Wang et al. ${ }^{\left({ }^{(8)}\right.}$ reported that there were no significant differences in HR or MAP at any point in time (T1 to T5) between the two groups $(P>0.05)$. Sharma and Gupta ${ }^{(9)}$ which aimed to compare the postoperative analgesic efficacy of three different concentrations of ropivacaine when instilled periportally just before closure in laparoscopic cholecystectomy, and reported that changes in heart rate, systolic blood pressure, diastolic blood pressure, respiratory rate, Spo2, sedation and PONV scores at various time intervals were also statistically not significant $(\mathrm{P}>0.05)$.

In the present study, we showed that there was significant increase in MAC and statistically significant increase in fentanyl consumption among cases in intraperitoneal instillation group than those cases of rectus sheath group. Our results are supported by the study of Gupta et al. ${ }^{(7)}$ who reported that the mean number of doses of rescue analgesic required by each patient over 48 hours postoperatively in control group was $5.96 \pm 0.45$ that was significantly higher than in group I $(4.04 \pm 0.67), \mathrm{p}<0.001$ and group $\mathrm{R}(2.96 \pm$ $1.09), \mathrm{p}<0.001$ as well as in group I $(4.04 \pm 0.67)$ as compared to group $\mathrm{R}(2.96 \pm 1.09), \mathrm{p}<0.001$. Thus, rescue analgesic consumption was reduced by $50.33 \%$ with RSB and $32.21 \%$ by intraperitoneal instillation as compared to control group. On the other hand, the study of Papadima et al. (10) reported that fentanyl consumption in the recovery room was significantly greater in the control group than that in cases who received intraperitoneal analgesic.

In the current study, we evaluated the postoperative first call for rescue analgesia hours among the two groups and we found that mean was $2.88 \pm 0.33$ hours in intraperitoneal instillation, while in rectus sheath block was $5.32 \pm 0.69$ hours. Thus, it is statistically significant longer among rectus sheath block group. This is in comparison with the study of Gupta et al. ${ }^{(7)}$ in which all patients in the three groups required rescue analgesic during postoperative period of 48 hours. The first dose of rescue analgesic was required significantly earlier in control group $(1.72 \pm 0.67$ hour $)$ as compared to intraperitoneal instillation group (7.84 \pm 1.34 hour), $p<0.001$ and rectus sheath block group (16.16 \pm 4.73 hour), $\mathrm{p}<0.001$. The difference was also significant between group of rectus sheath and intraperitoneal instillation group, $p<0.001$. In initial 6 hours postoperatively, all patients $(100 \%)$ of control group required rescue analgesic, while only $4(16 \%)$ patients in intraperitoneal instillation group, and no patient $(0 \%)$ in group of rectus sheath demanded for rescue analgesic. Abd El-Hamid et al. ${ }^{(5)}$ reported that regarding rescue analgesia, time to requirement of firstdose rescue analgesia in our study was longer in group LS than in group L and was minimum in patients of group $\mathrm{C}$, indicating better and longer pain relief in patients receiving levobupivacaine with sufentanil compared to patients receiving levobupivacaine alone and those receiving normal saline. Total analgesic consumption was also significantly lower in group LS and total analgesic consumption (diclofenac) was maximum in group $\mathrm{C}$. Therefore, levobupivacaine along with sufentanil reduces not only the intensity of pain but also the total dose of analgesic consumption.

In the current study, we found that there was statistical significant difference between the two groups as regards VAS at 30 minutes, 60, 90 minutes, 2hours, $4 \mathrm{~h}, 6 \mathrm{~h}, 12 \mathrm{~h}, 18 \mathrm{~h}$ and at $24 \mathrm{~h}$ postoperatively, which was more decreased among cases of rectus sheath block group. Our results are supported by the study of Kasem and AbdelKader ${ }^{(11)}$, where pain scores were similar during the early postoperative period up to $4 \mathrm{~h}$ and late at the time interval 18-24 h, whereas there was a significant difference between the study groups at the time intervals 6-8 and 10-12 h. Sandeman et al. ${ }^{(12)}$ reported that median pain scores were reduced for the TAP group in the recovery room only, but pain scores were similar at all other time intervals. Gurnaney et al. ${ }^{(13)}$ reported that pain scores at rest and with movement between the study groups did not show a significant difference. Moreover, Gupta et al. ${ }^{(7)}$ reported that mean VAS scores for abdominal pain showed a significant difference among the three groups during first 6 hours. At 2 hour postoperatively, mean VAS score was significantly higher in group $\mathrm{C}$ as compared to group I and group $\mathrm{R}$ while it was comparable between group I and group $\mathrm{R}$ (Group $\mathrm{C}>$ Group $\mathrm{I} \approx$ Group $\mathrm{R}$ ). At 4 hour postoperatively, mean VAS score was significantly higher in group $\mathrm{C}$ as compared to group I and group $\mathrm{R}$ as well as in group I as compared to group R. $\{$ group $\mathrm{C}>$ group $\mathrm{I}>$ group R\}. At 6 hour postoperatively, VAS score was significantly less in group $\mathrm{R}$ as compared to group $\mathrm{C}$ and group I. While there was no statistical difference in VAS scores between Group $\mathrm{C}$ and group $\mathrm{I}$ \{Group $\mathrm{C} \approx$ group $\mathrm{I}>$ group R .

After 6 hours, till 48 hours postoperatively, there was no significant difference in the VAS scores among the three groups. Wang et al. ${ }^{(8)}$ reported that the RSB also effectively relieved postoperative pain. In this study, we found that the VAS scores of pain at rest and during motion were all lower in the GR group than in the $\mathrm{G}$ group at $12 \mathrm{~h}$ after surgery. However, at $24 \mathrm{~h}$ and $48 \mathrm{~h}$ after surgery, there were no differences in the VAS 
scores of pain at rest and during motion between the two groups, suggesting that the analgesic effects of a single BRSB remained within $12 \mathrm{~h}$ after surgery.

In the current study, we found that there were no statistical significant differences between the two groups regarding anesthetic time, and surgical time, while there were highly statistical significant differences between the two groups as regards duration of the block, recovery time, and time taken for the block. It was lower among intraperitoeal instillation group. In agreement with our findings, Gupta et $\boldsymbol{a l} .{ }^{(7)}$ reported that there were no statistical significant differences between two groups as regard anesthetic time, and surgical time.

In the present study, we found that mean \pm SD. of patient satisfaction in intraperitoneal instillation group was $1.60 \pm 0.50$ and in rectus sheath group was $3.40 \pm 0.71$, and there was highly statistical significant difference between the two groups concerning satisfaction, which was increased among rectus sheath group. In agreement with our findings, Gupta et al. ${ }^{(7)}$ reported that there was significant difference in the patient satisfaction score among the three groups. In group R (RSB), 23(92\%) patients had acceptable patient satisfaction score (i.e., 5-7), whereas in group I 10 (40\%) patients, and in group C, only $5(20 \%)$ patients had acceptable patient satisfaction score, group $\mathrm{R}>$ group $\mathrm{I}>$ group $\mathrm{C} .(\mathrm{p}=0.000)$.

Finally, in the present study we found that mean total analgesic consumption postoperatively was 270.4 \pm 26.53 in intraperitoneal instillation group and was $66.40 \pm 31.51$ in rectus sheath block group, and there was highly statistical significant difference between the two groups. As regards total analgesic consumption, it was increased among intraperitoneal instillation group. In a harmony with our findings, Gupta et al. (7) demonstrated that mean total analgesic consumption postoperatively was increased significantly in intraperitoneal instillation group than in rectus sheath block group. Similar to our findings, Beder and Farahat ${ }^{(14)}$ reported that the mean of total analgesic consumption postoperatively was $117.8 \pm 63.7$ in intraperitoneal instillation group.

\section{CONCLUSION}

U/S-guided rectus sheath block is effective analgesic technique as intraperitoneal instillation of levobupivacaine with more patient satisfaction, lower postoperative pain and lower amount of anaesthetic consumption, both techniques are simple, safe, and without adverse effects. This study favors the administration of rectus sheath block pre-emptively for postoperative pain relief after laparoscopic cholecystectomy.

\section{REFERENCES}

1. Kim T, Kang H, Park J et al. (2010): Intraperitoneal ropivacaine instillation for postoperative pain relief after laparoscopic cholecystectomy. J Korean Surg Soc., 79: 130-36.

2. Shabir S, Saleem B, Hakim A et al. (2011): Postoperative analgesia in laparoscopic cholecystectomy: a comparative study using bupivacaine instillation and infiltration versus parenteral analgesia (tramadol). The Internet Journal of Anaesthesiology, 29: 2-6.

3. Issac L, McEwen J, Hayes J et al. (2006): A pilot study of the rectus sheath block for pain control after umbilical hernia repair. Paediatr Anaesth., 16: 406-09.

4. Shah V, Bajaj M (2019): Ultrasound guided rectus sheath block in management of pain in laparoscopic tubal ligation. Anaesthesia, Pain \& Intensive Care, 21: 436-8.

5. Abd El-Hamid A, El-Moutaz H, Abdel Moneim A (2016): Evaluation of intraperitoneal levobupivacaine with and without sufentanil for postoperative analgesia after laparoscopic cholecystectomy. Ain-Shams J Anaesthesiol. , 9:371-6.

6. Dolan J, Lccie P, Geary T et al. (2009): The rectus sheath block: accuracy of local anesthetic placement by trainee anesthesiologists using loss of resistance or ultrasound guidance. Reg Anaesth Pain Med., 34: 247250.

7. Gupta M, Naithani U, Singariya G et al. (2016): Comparison of $0.25 \%$ Ropivacaine for Intraperitoneal Instillation v/s Rectus Sheath Block for Postoperative Pain Relief Following Laparoscopic Cholecystectomy: A Prospective Study. Journal of Clinical and Diagnostic Research, 10 (8): 10-15.

8. Wang S, Liu P, Gao T et al. (2020): The impact of ultrasound-guided bilateral rectus sheath block in patients undergoing cytoreductive surgery combined with hyperthermic intraperitoneal chemotherapy - a retrospective study. BMC Anesthesiol., 20: 197-203.

9. Sharma P, Gupta A (2020): Comparative study of preclosure periportal instillation of three different concentrations of ropivacaine $(0.125 \%, 0.25 \%, 0.5 \%)$ for postoperative analgesia in laparoscopic cholecystectomy. International Journal of Contemporary Medical Research, 7 (2): 16-21.

10. Papadima A, Lagoudianakis E, Antonakis $P$ et al. (2009): Repeated intraperitoneal instillation of levobupivacaine for the management of pain after laparoscopic cholecystectomy. Surgery, 146 (3): 475-82.

11. Kasem A, AbdelKader A (2015): Ultrasound-guided rectus sheath block versus local infiltration in management of pain after single-incision laparoscopic cholecystectomy. Ain-Shams J Anaesthesiol., 8: 100-106.

12. Sandeman D, Bennett M, Dilley A et al. (2011): Ultrasound-guided transversus abdominis plane blocks for laparoscopic appendicectomy in children: a prospective randomized trial. Br J Anaesth., 106: 882886.

13. Gurnaney H, Maxwell L, Kraemer F et al. (2011): Prospective randomized observer-blinded study comparing the analgesic efficacy of ultrasound-guided rectus sheath block and local anaesthetic infiltration for umbilical hernia repair Br J Anaesth., 107: 790-95.

14. Beder El Baz M, Farahat T (2018): Intraperitoneal levobupivacaine alone or with dexmedetomidine for postoperative analgesia after laparoscopic cholecystectomy. Anesth Essays Res., 12: 355-8. 